\title{
SKRINING KESEHATAN PADA ANAK USIA SEKOLAH DI SDN 19 MENDOBARAT
}

\author{
Rezka Nurvinanda ${ }^{1}$, Rima Berti Anggraini ${ }^{2}$ \\ 1 STIKES Citra Delima Bangka Belitung \\ 2 STIKES Citra Delima Bangka Belitung
}

Email: rezkanurvinanda@gmail.com; rimabertianggraini@gmail.com

\begin{abstract}
ABSTRAK
Anak usia sekolah merupakan masa dimana terjadi perubahan yang bervariasi pada pertumbuhan dan perkembangan anak yang akan mempengaruhi kondisi kesehatan anak. Kegiatan skrining kesehatan yang dilakukan pada siswa dan siswi di SDN 19 Mendobarat bertujuan untuk mendeteksi dini anak yang memiliki masalah kesehatan agar segera mendapatkan penanganan sedini mungkin. Metode pelaksanaan pada kegiatan skrining kesehatan terdiri dari pemeriksaan kepala mencakup rambut, mata, hidung, telinga, mulut dan gigi, pemeriksaan kulit dan kuku, berat badan serta tinggi badan. Hasil skrining kesehatan sebagian besar siswa dan siswi SDN 19 Mendobarat mengalami masalah pada gigi, juga memiliki masalah dalam perawatan diri seperti kuku yang panjang dan kotor, telinga kotor, dan kulit yang kurang bersih. Tetapi mayoritas anak memiliki kebersihan diri yang baik. Kesimpulannya masalah kesehatan terkait kebersihan diri apabila tidak dilakukan penatalaksanaan yang baik dapat menimbulkan berbagai dampak yang dapat mengganggu aktivitas anak usia sekolah sehingga penting untuk dilakukan skrining kesehatan dan pendidikan kesehatan.
\end{abstract}

Kata Kunci: Anak, Skrining Kesehatan, Usia Sekolah

\section{ABSTRACT}

School-age children are a time when there are various changes in children's growth and development that will affect the child's health condition. The health screening activities carried out on students at SDN 19 Mendobarat aims to detect children who have health problems early so that they can get treatment as early as possible. The implementation method for health screening activities consists of examination of the head covering hair, eyes, nose, ears, mouth and teeth, examination of skin and nails, body weight and height. The results of health screening, most of the students at SDN 19 Mendobarat experienced problems with their teeth, as well as problems in self-care such as long and dirty nails, dirty ears, and unclean skin. But the majority of children have good personal hygiene. In conclusion, health problems related to personal hygiene if good management are not carried out can have various impacts that can interfere with school age children activities so it is important to carry out health screening and health education.

Keywords: Children, Health Screening, School Age. 


\section{PENDAHULUAN}

Salah satu permasalahan serius yang dihadapi bangsa Indonesia adalah masalah kesehatan khususnya masalah kesehatan anak usia sekolah. Populasi anak usia sekolah dasar merupakan komponen yang cukup penting dalam masyarakat, mengingat jumlahnya yang cukup besar diperkirakan $23 \%$ atau sepertiga dari jumlah penduduk Indonesia (Prasetyo, 2014).

Anak usia sekolah yaitu anak usia 6-12 tahun yang mempunyai sifat individual serta aktif merupakan masa dimana terjadi perubahan yang bervariasi pada pertumbuhan dan perkembangan anak yang akan mempengaruhi kondisi kesehatan anak (Diyantini et al., 2015).

Karakteristik anak usia sekolah yaitu anak usia sekolah yang sehat memiliki ciri diantaranya adalah banyak bermain di luar rumah, melakukan aktivitas fisik yang tinggi, serta beresiko terpapar sumber penyakit dan perilaku hidup yang tidak sehat (Hardiansyah dan Supariasa, 2016)

Beberapa kebiasaan anak yang dapat mempengaruhi kondisi kesehatan anak khususnya di sekolah yaitu pola makan anak, kebiasaan mencuci tangan, kebersihan telinga, kebersihan kulit, kebersihan kuku, kebersihan rambut, mandi dan juga kebiasaan anak jajan sembarangan (Kwureh, 2016).

Anak dalam usia sekolah disebut sebagai masa intelektual dimana anak mulai belajar berpikir secara konkrit dan rasional. Tugas perkembangan anak dalam usia sekolah adalah belajar mengambangkan kebiasaan untuk memelihara badan meliputi kesehatan dan kebersihan diri, serta terdapat hubungan yang positif antara jasmani dengan prestasi dimana apabila tubuh anak sehat maka banyak prestasi belajar yang dapat dicapai (Yusuf, 2008 dalam Suhri dan Sulastri, 2014)

Berdasarkan latar belakang tersebut maka dilakukan skrining kesehatan pada anak kelas 1 SDN 19 Mendobarat. Skrining kesehatan berupa pemeriksaan kesehatan dapat membantu mengurangi resiko penyakit yang ditimbulkan dari perawatan diri yang kurang baik dan perilaku hidup yang tidak sehat. Kegiatan ini bertujuan untuk mendeteksi dini anak yang memiliki masalah kesehatan agar segera mendapatkan penanganan sedini mungkin. Pemeriksaan kesehatan ini terdiri dari pemeriksaan kepala mencakup rambut, mata, hidung, telinga, mulut dan gigi, pemeriksaan kulit dan kuku, berat badan serta tinggi badan.

\section{MASALAH}

Perlunya skrining kesehatan pada anak sekolah dasar kelas 1 di SDN 19 Mendobarat sebagai upaya promotif dan preventif terhadap resiko kondisi kesehatan pada anak usia sekolah yang dapat berdampak bagi tumbuh kembang anak.

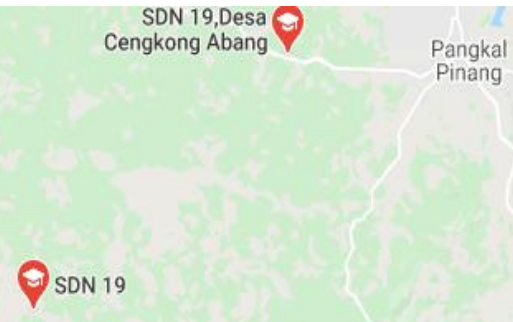

Map data $\oplus 2020$

Gambar 2.1 Lokasi Skrining Kesehatan SDN 19 Maendobarat 


\section{METODE}

1. Tahap Persiapan

Tahap persiapan dimulai dengan permohonan izin kepada kepala sekolah SDN 19 Mendobarat dengan menjelaskan tujuan pelaksanaan skrining kesehatan, persiapan alat-alat dan tempat pelaksanaan skrining kesehatan.

2. Tahap Pelaksanaan

a. Metode pelaksanaan pada kegiatan skrining kesehatan adalah mengukur tinggi badan menggunakan pengukur tinggi badan. Kemudian mengukur berat badan dengan menggunakan timbangan badan digital, selanjutnya melakukan pemeriksaan kebersihan rambut, mata, hidung, mulut dan gigi, telinga menggunakan otoskop serta kebersihan kulit dan kuku.

b. Mencatat hasil pemeriksaan pada buku monitoring skrining kesehatan anak yang telah disediakan dengan memberikan catatan rekomendasi pemeriksa bagi orangtua anak.

3. Evaluasi

a. Struktur

Seluruh anak kelas 1 SDN 19 Mendobarat ikut dalam skrining kesehatan yaitu sebanyak 27 anak yang terdiri dari 17 anak laki-laki dan 10 anak perempuan. Tempat pelaksanaan skrining kesehatan dilakukan di dalam ruang kelas 1 SDN 19 Mendobarat. Semua peran sudah dijalankan sesuai dengan tugas yang telah dibagikan, baik sebagai penanggung jawab, pemeriksa, observasi, fasilitator dan dokumentasi.

b. Proses

Pelaksanaan kegiatan skrining kesehatan dilaksanaan pada pukul $09.00 \mathrm{~s} / \mathrm{d} 11.00$ WIB sesuai dengan jadwal yang telah direncanakan.

c. Hasil

Seluruh anak kelas 1 SDN 19 Mendobarat telah menjalani pemeriksaan skrining kesehatan dengan baik, dan hasilnya telah didokumentasikan dalam buku monitoring skrining kesehatan masing-masing anak.

\section{HASIL DAN PEMBAHASAN}

Seluruh siswa dan siswi SDN 19 Mendobarat yang telah mengikuti skrining kesehatan mayoritas berjenis kelamin laki-laki sebanyak 17 anak (62,96\%) dan perempuan sebanyak 10 anak (37,03\%).

Berdasarkan hasil skrining kesehatan sebagian besar anak mengalami masalah pada gigi, yaitu karies gigi dan gigi berlubang. Beberapa anak yang lain juga memiliki masalah dalam perawatan diri seperti kuku yang panjang dan kotor, telinga kotor, dan kulit yang kurang bersih. Tetapi mayoritas anak memiliki kebersihan diri yang baik.

Saat pemeriksaan kesehatan berlangsung siswa dan siswi kelas 1 SDN 19 Mendobarat sangat bersemangat untuk dilakukan pemeriksaan kesehatan sambil belajar sabar dan antri untuk menunggu giliran. Saat kegiatan berlangsung selalu didampingi oleh wali kelas sampai dengan kegiatan selesai. 

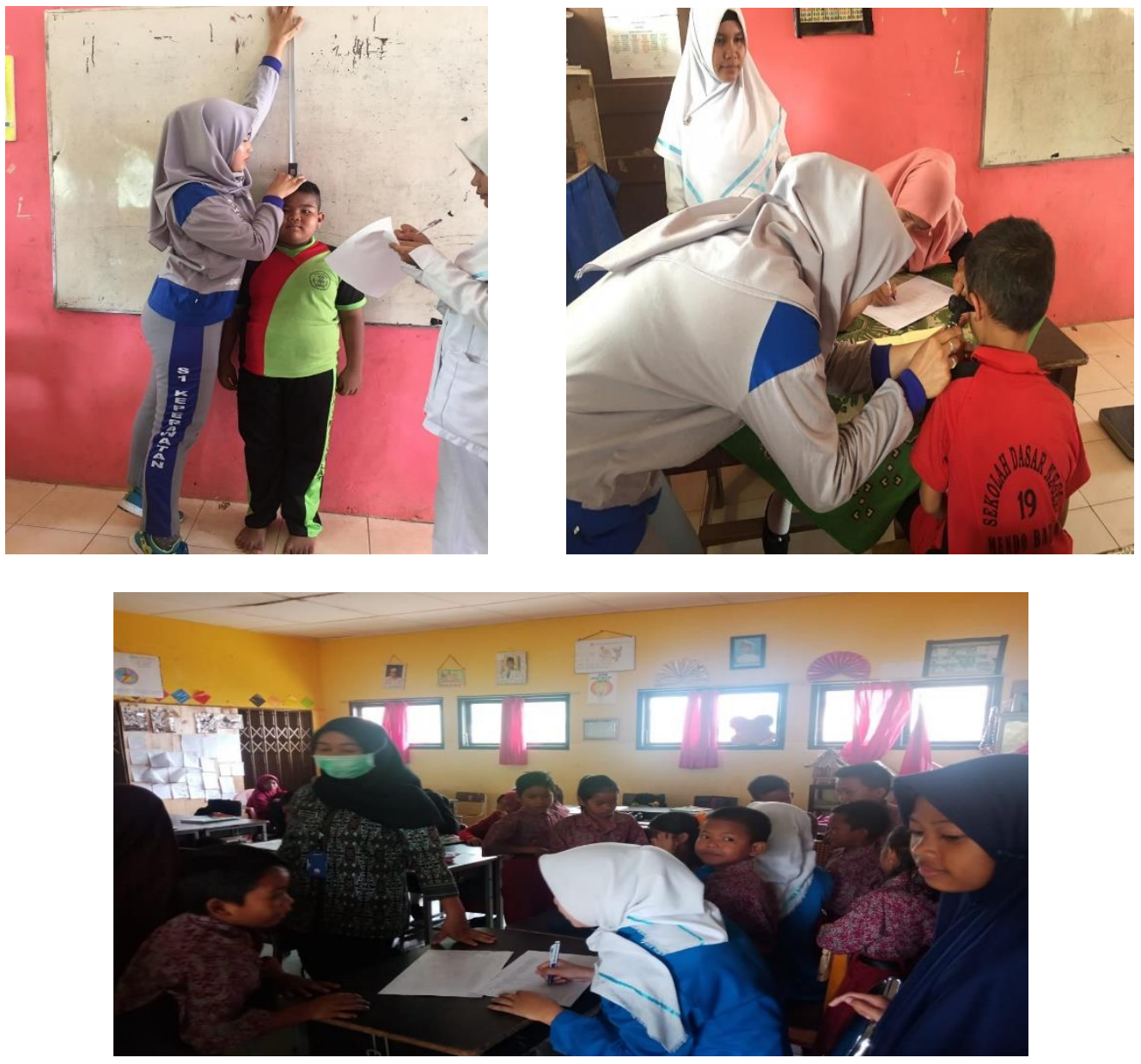

Gambar 4.1 Pelaksanaan Skrining Kesehatan

Kondisi kesehatan yang jika tidak ditangani atau tidak dikelola dapat mengganggu kemampuan anak untuk belajar di sekolah (Gracy et al., 2018). Sekolah dengan kondisi air, sanitasi dan kebersihan yang buruk, sertatingkat kontak orang ke orang yang sering merupakan lingkungan yang berisiko tinggi untuk anak-anak yang rentan terhadap kondisi kesehatan lingkungan yang tidak baik (Mane, Kakade, \& Alate, 2019). Ditambah lagi, masalah dan perilaku kesehatan yang buruk (seperti ketidakaktifan fisik dan gizi buruk) berhubungan terhadap hasil pendidikan yaitu berpengaruh pada persepsi sensorik, kognisi, dan hal yang berkaitan dengan sekolah, ketidakhadiran, serta putus sekolah (Michael et al., 2015).

Rekomendasi perawatan primer pediatrik untuk anak-anak usia sekolah termasuk pemeriksaan kesehatan anak rutin setiap tahun dengan riwayat lengkap, pemeriksaan fisik, panduan antisipatif (pendidikan kesehatan yang sesuai usia untuk mempromosikan kesehatan dan mencegah penyakit dan cedera), dan skrining yang ditargetkan (American Academy of Pediatrics, 2017).

Jika semua anak menerima pemeriksaan anak sehat rutin setiap tahun, dan semua penyedia layanan kesehatan mengikuti pedoman praktik terbaik, anak-anak akan dilakukan skrining secara teratur untuk mengetahui hambatan atau masalah kesehatan selama masa belajar(NSCH, 2014 dalam Gracy et al., 2018). 
Kesehatan masa sekolah dapat membantu meningkatkan kualitas pendidikan dan potensi untuk membantu siswa mencapai literasi kesehatan, meningkatkan perilaku yang berhubungan dengan kesehatan sehingga meningkatkan status kesehatan siswa itu sendiri (Sherman \& Muehlhoff, 2017).

\section{KESIMPULAN}

Anak usia sekolah memiliki resiko kesehatan terkait kurang tepatnya dalam melakukan perawatan diri secara komprehensif. Berbagai masalah kesehatan yang sering timbul akibat kurangnya menjaga kebersihan diri antara lain masalah kesehatan mulut dan gigi, kuku, kulit dan tubuh yang kurang bersih. Masalah kesehatan terkait kebersihan diri apabila tidak dilakukan penatalaksanaan yang baik dapat menimbulkan berbagai dampak yang dapat mengganggu aktivitas anak usia sekolah sehingga penting untuk dilakukan skrining kesehatan dan pendidikan kesehatan.

\section{DAFTAR PUSTAKA}

American Academy of Pediatrics. In: Recommendations for Preventive Pediatric Health Care. (2017). Diakses dari: https: / /www.aap.org/enus/Documents/periodicity_schedule.pdf

Diyanti, A. O., Amiuza, C. B., \& Mustikawati, T. (2015). Lingkungan Ramah Anak pada Sekolah Taman Kanak-Kanak. RUAS (Review of Urbanism and Architectural Studies), 12(2), 54-68.

Gracy, D., Fabian, A., Basch, C. H., Scigliano, M., MacLean, S. A., MacKenzie, R. K. , \& Redlener, I. E. (2018). Missed opportunities: Do states require screening of children for health conditions that interfere with learning?. Plos one, 13(1), e0190254.

Hardiansyah., \& Supariasa. (2016). Ilmu Gizi Teori \& Aplikasi. Jakarta: Buku Kedokteran EGC

Mane, D. A., Kakade, S. V., \& Alate, M. M. (2019). School health screening program at Khubi village of Western Maharashtra: a comparative study. International Journal of Science \& Healthcare Research, 4(1), 7-11.

Michael, S. L., Merlo, C. L., Basch, C. E., Wentzel, K. R., \& Wechsler, H. (2015). Critical connections: health and academics. Journal of School Health, 85(11), 740-758.

Prasetyo, Y. B. (2014). Pelaksanaan Program Usaha Kesehatan Sekolah Dalam Upaya Meningkatkan Derajat Kesehatan Pada Anak Usia Sekolah Dasar di Lombok Timur. YARSI medical Journal, 22(2), 102-113.

Sherman, J., \& Muehlhoff, E. (2017). Developing a nutrition and health education program for primary schools in Zambia. Journal of Nutrition Education and Behavior, 39(6), 335-342.

Suhri, M., Sudaryanto, A., Ns, M. K., \& Sulastri, S. (2014). Gambaran Sikap Tentang Perilaku Hidup Bersih Dan Sehat Pada Anak Sekolah Dasar Negeri Di Desa Gonilan Kecamatan Kartasura Kabupaten Sukoharjo (Doctoral dissertation, Universitas Muhammadiyah Surakarta).

Kwureh, H. N. (2016). Hubungan Jenis Kelamin, Pengetahuan, Sikap Dan Peran Guru Dengan Perilaku Hidup Bersih Dan Sehat Pada Siswa. Wawasan Kesehatan: Jurnal Ilmiah Ilmu Kesehatan, 2(1). 